\title{
Benarkah Self Compassion dapat Mengurangi Gejala Body Dysmorphic Disorder?
}

\author{
Dea Nada Fatmala ${ }^{1}$, Martaria Rizky Rinaldi ${ }^{2}$ \\ ${ }^{12}$ Fakultas Psikologi, Universitas Mercu Buana Yogyakarta \\ Jl Wates KM 10 Yogyakarta, 55753 \\ 1'deanadafatmala@gmail.com, ${ }^{2}$ martariarizky@mercubuana-yogya.ac.id
}

\begin{abstract}
Abstrak
Penelitian ini bertujuan untuk mengetahui hubungan antara self compassion dengan gejala body dysmorphic disorder pada remaja putri. Hipotesis yang diajukan dalam penelitian ini adalah ada hubungan negatif antara self compassion dengan gejala body dysmorphic disorder. Subjek dalam penelitian ini ber jumlah 105 orang. Pengambilan subjek menggunakan purposive sampling, data dikumpulkan menggunakan skala Self Compassion dan skala Gejala Body Dysmorphic Disorder. Analisis data penelitian ini menggunakan korelasi product moment dari Pearson. Berdasarkan hasil analisis, diperoleh koefisien korelasi (rxy) = -0,336 ( $<<0,005)$. Hasil tersebut menunjukkan bahwa terdapat hubungan negatif yang signifikan antara self compassion dengan gejala body dsymorphic disorder. Artinya semakin tinggi self compassion yang dilakukan individu maka semakin rendah gejala body dysmophic disorder yang dimilikinya, sebaliknya semakin rendah self compassion maka semakin rendah gejala body dysmorphic disorder yang dimiliki individu. Koefisien determinasi ( $\mathrm{R}^{2}$ ) yaitu 0,113 yang menunjukkan sumbangan efektif $11,3 \%$ dari self compassion untuk gejala body dysmorphic disorder.
\end{abstract}

Kata kunci : self compassion, gejala body dysmorphic disorder

\begin{abstract}
This study aims to determine the relationship between self-compassion and symptoms of body dysmorphic disorder in young women. The hypothesis proposed in this study is that there was a negative relationship between self-compassion and symptoms of body dysmorphic disorder. Subjects in this study were 105 people. Subjects were taken using purposive sampling, data were collected using the Self Compassion scale and the Body Dysmorphic Disorder Symptoms scale. The data analysis of this study used Pearson's product-moment correlation. Based on the analysis, the correlation coefficient (rxy) $=-0.336(p<0.005)$ was obtained. These results indicate that there is a significant negative relationship between self-compassion and symptoms of body dysmorphic disorder. This means that the higher the self-compassion carried out by the individual, the lower the symptoms of body dysmorphic disorder they have, conversely, the lower the self-compassion, the lower the symptoms of body dysmorphic disorder the individual has. The coefficient of determination (R2) is 0.113 which indicates an effective contribution of $11.3 \%$ of self-compassion for symptoms of body dysmorphic disorder.
\end{abstract}

Keyword : self compassion, the indication of body dysmorphic disorder

\section{PENDAHULUAN}

Masa remaja dimulai masa kanak-kanak yang beralih menuju masa dewasa, adapun perubahan yang ditunjukan seperti perubahan tinggi badan, berat badan (perubahan fisik) maupun perubahan tingkah laku, siap, mental (perubahan psikis) (Santrock, 2012). Perubahan psikis, seperti emosi yang dapat berubah seketika (Hurlock, 2003). Maupun perubahan fisik yaitu meningginya badan, serta kaki dan tangan yang bertambah panjang (Sigelman \& Rider, 2018). Remaja yang terlalu menghayati perubahan tubuhnya sebagai sesuatu yang terlihat aneh, asing dan ganjil sehingga remaja cenderung mengkhawatirkan ketidaksempurnaan tubuhnya (Muller dalam Santrock, 2012). Remaja yang merasa mempunyai ukuran badan terlalu besar, tinggi badan yang tidak proporsional dan tidak sesuai dengan harapan, merasa 
dirinya kurang menarik dan cenderung kurang percaya diri (Fitri, Nilma \& Ifdil, 2018). Ukuran tubuh yang menunjukkan kelebihan berat badan juga sering diasosiasikan sebagai kemalasan dan kelemahan dalam budaya tertentu (Papalia, Old, \& Feldman, 2008).

Pengaruh dari global culture juga mempengaruhi individu dalam menilai tubuhnya, baik pada remaja laki-laki maupun perempuan (Gracia \& Akbar, 2019). Perempuan Indonesia memiliki kecantikan alami yang khas, seperti memiliki warna kulit sawo matang (Wirasari, 2016), namun kenyataannya terdapat pergeseran persepsi tentang kecantikan di Indonesia, dari kulit sawo matang, anggun seperti putri keraton menjadi kulit putih yang berpesona Barat (Yulianto, 2007). Hasil studi meta-analisis yang dipaparkan oleh media juga telah menciptakan pola pikir sosial yang mengindikasikan bahwa perempuan yang kurus dan berkulit putih adalah perempuan yang cantik (Wade \& Tavris, 2008)

Pada masa perkembangan remaja terdapat tugas-tugas yang harus dipenuhi, salah satu tugas perkembangan pada masa remaja yang harus dipenuhi adalah bagaimana remaja dapat menerima bentuk tubuhnya sehingga remaja dapat secara efektif memanfaatkan bentuk tubuhnya (Sarwono, 2006). Realitas yang ada menunjukkan bahwa pada masa remaja, 40-50\% perempuan cenderung ingin menjadi lebih kurus, hanya $10 \%$ perempuan yang ingin memiliki tubuh yang lebih berisi (Wertheim \& Paxton, 2011). Ketidakpuasan terhadap bentuk tubuh dapat membuat remaja perempuan mengembangkan perilaku maladaptif apabila tidak berhasil melalui masa remajanya dengan baik (Gracia \& Akbar, 2019). Hal ini menunjukkan gejala dari salah satu gangguan yang disebut body dismorphic disorder (BDD).

Phillips (2009) mendefinisikan body dysmorphic disorder sebagai gangguan ketika individu berlarut-larut dalam memikirkan tentang penampilan diri sendiri yang dinilai kurang. Hal tersebut membuat individu merasakan kekhawatiran yang berlebihan ketika merasa ada kelainan dalam penampilan fisiknya. Menurut American Psychiatric Association (2013) body dysmorphic disorder adalah gangguan yang ditunjukkan dengan kekhawatiran yang berlebihan dalam mempersepsikan kekurangan atau kecacatan dalam penampilan fisik seseorang yang menyebabkan penurunan fungsi sosial.

Salah satu faktok yang menyebabkan remaja perempuan yang menunjukkan gejala body dysmorphic disorder adalah sifat dan nilai kepribadian, biasanya individu cenderung perfeksionis dan ingin dipandang sempurna terutama pada penampilannya (Phillips, 2009). Kepribadian individu merupakan salah satu historical factor dari body image (Cash, 2008). Salah satu atribut kepribadian adalah self-esteem yang menjadi faktor penting bagi perkembangan body image seseorang. Self-esteem dapat memfasilitasi evaluasi positif terhadap tubuh dan sebaliknya, self-esteem yang buruk dapat meningkatkan seseorang rentan memiliki body image yang negatif (Cash \& Fleming, 2002). Menurut Kharina dan Saragih (2012) semua manusia selalu berusaha menjadi yang terbaik agar mencapai self-esteem yang tinggi. Keinginan untuk mempertahankan tingginya self-esteem dari dirinya membuat individu selalu memandang dirinya lebih baik dari yang sebenarnya (Repi, 2019). Konsep baru mengenai sikap yang lebih sehat untuk menilai diri sendiri tanpa melibatkan evaluasi diri ataupun perbandingan sosial, menggunakan self-compassion (Kharina \& Saragih, 2012). Peran penting dari konsep self-compassion yang siap "menjaga" diri individu dan membentuk emosi positif sehingga, individu tidak jatuh dalam keterpurukan akibat berbagai respon negatif lingkungan terhadap dirinya (Neff, 2003). Individu membutuhkan hal yang positif untuk mengatasi adanya gejala body dysmorphic disorder salah satunya adalah self compassion. 
Self-compassion adalah bagaimana individu dapat memahami dan memberi kebaikan pada diri sendiri ketika menghadapi masa - masa sulit ataupun pada saat individu melakukan kesalahan dengan tidak mencoba menghakimi diri sendiri, tidak mengkritik diri sendiri secara berlebihan dan mau mengakui bahwa semua itu adalah bagian dari pengalaman diri yang umum terjadi (Neff, 2003). Ada tiga hal dasar yang membuat Self-compassion dapat membantu individu menghindari gejala body dysmorphic disorder.

Pertama, Self-kindness atau kebaikan diri adalah kemampuan untuk memahami diri ketika individu memiliki kekurangan ataupun merasakan penderitaan dalam hidupnya. Sehingga komponen ini menerangkan seberapa jauh individu dapat memahami, memaknai kegagalannya dan tidak mengkritik diri atas peristiwa menyakitkan yang dialami. Dalam aspek ini menerangkan seberapa jauh seseorang dapat memahami dan memaknai kegagalannya. Self kindness mengajarkan kepada diri sendiri agar merasa bahwa dirinya pantas untuk mendapatkan cinta, kebahagiaan, sehingga menciptakan rasa kenyamanan dan tidak menyakiti diri sendiri atau menghakimi diri sendiri (self-judgement). Dengan adanya self-kindness individu akan membuat kedamaian dalam hidupnya dengan menenangkan pikirian, kelembutan dan simpati kepada diri sendiri.

Berikutnya ada Common humanity atau sifat manusiawi adalah individu mampu melihat kegagalan sebagai sesuatu yang wajar dan dialami oleh setiap manusia sehingga tidak perlu menyalahkan diri sendiri. Melalui common humanity seseorang akan mampu melihat sebuah kegagalan atau masalah merupakan bagian dari hidup manusia dan merupakan sesuatu yang harus dialami oleh semua orang, bukan hanya dialami diri sendiri. Individu akan dapat memahami bahwa setiap manusia mengalami kesulitan dan masalah dalam hidupnya

Mindfulness merupakan bagian dari self compassion terakhir yang di perlukan individu untuk menghindari gejala body dysmorphic disorder. Mindfulness atau kesadaran penuh atas situasi saat ini, merupakan kemampuan menyeimbangkan pikiran ketika dalam situasi yang menekan atau menimbulkan penderitaan. Artinya individu mampu melihat segala sesuatu yang terjadi dalam keadaan yang sebenar benarnya tanpa dilebih-lebihkan ataupun dikurangkurangkan. Melalui mindfulness individu akan dapat sepenuhnya mengetahui dan mengerti apa yang sebenarnya dirasakan oleh dirinya sendiri. Mindfulness berlawanan dengan komponen Over identification yakni reaksi berlebihan yang ditunjukkan individu dalam menghadapi permasalahan. Individu dengan Over identification cenderung terlalu fokus pada keterbatasan diri sehingga pada akhirnya menimbulkan kecemasan dan depresi.

Melalui self-kindness, common humanity, maupun mindfulness, menurut Albertson, Neff dan Dill-Shackleford (2015), self-compassion dapat menjadi faktor moderasi terhadap intensitas persepsi negatif terkait penampilan. Self-compassion dinilai efektif dapat membantu individu untuk dapat lebih menyayangi diri sendiri dan tidak menghakimi, menyalahkan diri sendiri saat individu memiliki kekurangan (Anggraheni \& Rahmandani, 2019). Intervensi berbasis self-compassion dinilai efektif dalam meningkatkan body image, sehingga individu memiliki penilaian yang lebih positif terhadap tubuhnya (Albertson, dkk., 2014). Penelitian mengungkap bahwa rendahnya self compassion berkaitan dengan tingginya malu dan ketidakpuasan pada citra tubuh yang kemudian memunculkan gejala gangguan makan (Ferreira, Pinto-Gouveia, \& Duarte, 2013). Penelitian yang berfokus pada body dysmorphic disorder masih minim, oleh karena itu, peneliti tertarik untuk meneliti hubungan antara self compassion dengan gejala body dismorphic disorder.

\section{METODE}


Partisipan dalam penelitian ini yaitu remaja perempuan yang tinggal di Indonesia. Kriteria usia yaitu usia $12-18$ tahun dengan tingkat pendidikan SMP sampai SMA. Alat pengumpulan data yang digunakan yaitu Skala Self Compassion dari Ilma dan Astuti (2020) dan Skala Gejala Body Dysmorphic Disorder dari Tandy dan Sukamto (2013) dengan model Skala Likert. Skala kecenderungan body dysmorphic disorder terdiri dari 42 aitem pernyataan, dengan rincian 24 aitem pernyataan favorable dan 18 aitem unfavorable. skala kecenderungan body dysmorphic disorder ini pernah diuji cobakan kepada 80 mahasiswa di Universitas " $\mathrm{X}$ " dengan koefisien reliabilitas Coronbach's Alpha sebesar 0,932 dan koefisien uji daya beda bergerak dari 0,312 sampai 0,734 (Tandy \& Sukamto, 2013). Skala Self compassion terdiri dari 21 aitem pernyataan, dengan rincian 8 aitem favorable dan 13 aitem pernyataan unfavourable. Skala Self-compassion ini pernah diuji cobakan kepada 76 subjek dengan kriteria umur 19-30 tahun. Dengan koefisien reliabilitas Coronbach's (a) sebesar .870 dan koefisien uji daya beda bergerak dari 0,263 sampai 0,737 (Ilma \& Astuti, 2020).

\section{HASIL}

\section{Tabel 1.}

Deskripsi Data Penelitian Hipotetik dan empirik

\begin{tabular}{ccccccccc}
\hline \multicolumn{4}{c}{ Data Hipotetik } & \multicolumn{4}{c}{ Data Empirik } \\
\hline Variab & Mean & Min & Max & SD & Mean & Min & Max & SD \\
\hline Gejala BDD & 105 & 42 & 168 & 21 & 104,78 & 90 & 118 & 5,216 \\
\hline Self compassion & 52,5 & 21 & 84 & 10,5 & 55,29 & 30 & 78 & 8.030 \\
\hline
\end{tabular}

Berdasarkan tabel 1 yang menunjukkan hasil analisis dari data empirik skala gejala body dysmorphic disorder diperoleh skor minimum 90 dan skor maksimum 118 dengan rata - rata empirik 104,78 dan standar deviasi 5,216. Hasil analisis data empirik skala self compassion diperoleh skor minimum 30, skor maksimum 78 dengan rata - rata empirik 55,29 dan standar deviasi 8,030.

Hasil uji normalitas variabel gejala body dysmorphic disorder diperoleh $\mathrm{KS}-\mathrm{Z}=0,57$ dengan $\mathrm{p}=0,200$ dan variabel self compassion diperoleh $\mathrm{KS}-Z=0,84$ dengan $\mathrm{p}=0,067$. Data tersebut menunjukkan bahwa skor variabel gejala body dysmorphic disorder dan self compassion terdistribusi normal. Sedang hasil analisis linearitas menujukkan bahwa hubungan antara variabel self compassion dengan gejala body dysmorphic disorder merupakan hubungan yang linier dengan $\mathrm{F}=12,695(\mathrm{p}=0,001, \mathrm{p}<0,050)$.

Pada penelitian hasil analisis korelasi product moment (pearson correlation) diperoleh koefisien korelasi $\left(\mathrm{r}_{\mathrm{xy}}\right)=-, 336(\mathrm{p}=0,000, \mathrm{p}<0,005)$ berarti menunjukkan adanya hubungan negatif antara self compassion dengan gejala body dsymorphic disorder. Artinya hipotesis dalam penelitian ini diterima. Diterimanya hipotesis menunjukkan bahwa semakin tinggi self compassion maka semakin rendah gejala body dsymorphic disorder dan sebaliknya semakin rendah self compassion maka semakin tinggi body dsymirphic disorder. Diterimanya hipotesis ini menunjukan koefesien determinasi $\left(\mathrm{R}^{2}\right)$ sebesar 0,113 yang menunjukkan bahwa sumbangan self compassion terhadap gejala body dysmorphic disorder hanya sebesar $11,3 \%$ -

Sebagai tambahan, hasil dari kategorisasi variabel gejala body dysmorphic disorder menunjukkan bahwa terdapat 100\% (105 subjek) berada pada kategori sedang. Variabel self compassion menunjukkan bahwa terdapat 1,92\% (2 subjek) berada dalam kategori tinggi, $95,23 \%$ (100 subjek) berada pada kategori sedang dan 2,85\% (3 subjek) berada dalam kategori rendah. Hasil kategorisasi tersebut menunjukkan bahwa sebagian besar remaja perempuan 
yang mengikuti penelitian ini memiliki self compassion dan gejala body dysmorphic disorder yang sedang.

Tabel 2.

Ketegorisasi Hasil Skala Gejala Body Dysmorphic Disorder

\begin{tabular}{ccccc}
\hline \multirow{2}{*}{ Kategori } & \multicolumn{2}{c}{ Body Dysmorphic Disorder } & \multicolumn{2}{c}{ Self compassion } \\
\cline { 2 - 5 } & $\mathrm{N}$ & Persentase & $\mathrm{N}$ & Persentase \\
\hline Tinggi & 0 & $0 \%$ & 2 & $1,92 \%$ \\
Sedang & 105 & $100 \%$ & 100 & $95,23 \%$ \\
Rendah & 0 & $0 \%$ & 3 & $2,85 \%$ \\
\cline { 2 - 5 } & 105 & $100 \%$ & 105 & $100 \%$ \\
\hline
\end{tabular}

Berdasarkan tabel 2 menunjukkan bahwa sebanyak 105 orang (100\%) remaja perempuan mengalami gejala body dysmorphic disorder sedang dan 100 orang $(95,23 \%)$ remaja perempuan memiliki self compassion sedang.

\section{DISKUSI}

Hasil penelitian ini menunjukkan adanya hubungan negatif antara self compassion dengan gejala body dysmorphic disorder. Korelasi negatif antara self compassion dengan gejala body dysmorphic disorder dalam penelitian ini sesuai dengan penelitian Veale dan Gilbert (2014) tentang self compassion dan gejala body dysmorphic disorder yang menunjukkan bahwa ketika individu memiliki self compassion, maka pikiran dan perilaku maladaptif yang menunjukkan gejala body dysmorphic disorder cenderung berkurang. Individu akan mengakui dan menerima kekurangannya, memikirkan perspektif lain yang lebih baik mengenai tubuhnya, cenderung berbuat baik dan menyayangi diri sendiri (Gilbert, 2005). Hasil penelitian ini juga sejalan dengan hasil penelitian Allen, Roberts, Gembeck, dan Farrell (2020) yang menunjukkan bahwa individu dengan self compassion yang tinggi memiliki gejala body dysmorphic disorder yang rendah. Selain itu, penelitian Foroughi, Khanjani dan Mousavi (2019) juga menunjukkan bahwa self compassion memiliki hubungan yang negatif dengan body dysmorphia.

Self compassion merupakan pemahaman dan kebaikan terhadap diri sendiri, yang berfungsi untuk menumbuhkan self kindness, yaitu kemampuan untuk menerima bahwa individu memiliki kekurangan dalam hidupnya (Neff, 2003), sehingga individu mampu untuk menghadapi tekanan dalam berpenampilan dengan cara tidak menghakimi diri sendiri (Ferreira, Pinto-Gouveia, \& Duarte, 2013). Hasil penelitian ini menunjukkan bahwa sebagian besar remaja pada penelitian ini memiliki self compassion yang cukup baik, hal ini sesuai dengan kategorisasi self compassion yang menunjukkan bahwa 95,23\% remaja berada pada kategori sedang.

Hasil penelitian Braun, Park dan Gorin (2016) menunjukkan bahwa individu yang memiliki self compassion tinggi cenderung mampu menerima kondisi tubuh. Selain itu, Rodgers, dkk (2017) menunjukkan bahwa komponen positif dari self compassion berhubungan dengan rendahnya body comparisons. Rendahnya body comparisons berkaitan dengan rendahnya gejala body dysmorphic disorder. Berdasarkan hasil penelitian, kategorisasi gejala body dysmorphic disorder pada subjek penelitian menunjukkan bahwa $100 \%$ subjek berada pada kategori sedang, hal tersebut menunjukkan bahwa sebagian besar remaja perempuan 
memiliki gejala body dysmorphic disorder. Gejala tersebut bisa jadi hanya gejala awal yang menunjukkan subjek kurang puas dengan tubuh atau keinginan untuk memiliki tubuh yang lebih cantik dan ideal, namun demikian perlu assessment lebih lanjut untuk menentukan diagnosis body dysmorphic disorder.

Individu yang memiliki self compassion mampu melihat kegagalan atau kekurangan merupakan sesuatu yang wajar dan dimiliki setiap manusia (Neff, 2003). Hal tersebut dapat membuat individu mampu menerima diri sendiri dan mengurangi frekuensi individu dalam membandingkan penampilannya dengan orang lain (Rodgers, dkk, 2017). Sedangkan, individu yang memiliki self compassion yang rendah cenderung merasa dirinya paling menderita (Neff, 2003), bahkan berlebihan saat menilai kekurangan yang dimiliki (Raes, Pommier, Neff, \& VanGucth, 2011). Hal ini menggambarkan bahwa self compassion mampu mempengaruhi gejala body dysmorphic disorder. Self compassion yang tinggi dapat menurunkan gejala body dysmorphic disorder, sedangkan self compassion yang rendah dapat meningkatkan gejala body dysmorphic disorder (Allen, dkk, 2020). Selain itu, komponen positif dari self compassion dapat menurunkan kecenderungan membandingkan diri dengan penampilan orang lain, berlarut-larut dalam melihat kekurangan fisik dan ketidakpuasan akan tubuh individu (Rodgers, dkk., 2017). Dalam penelitiannya Moran (2017) mengungkapkan program pengobatan yang meningkatkan rasa welas asih (self compassion) dan kampanye literasi media, disarankan untuk melindungi remaja dari konsekuensi negatif yang terkait dengan situs jejaring sosial yang maladaptif. Dengan demikian, self compassion dapat menjadi langkah pencegahan bagi individu untuk menghindari maupun mengurangi gejala body dysmorphic disorder.

\section{KESIMPULAN}

Berdasarkan hasil penelitian dapat diketahui bahwa self compassion yang dilakukan individu memiliki peranan dalam mengurangi gejala body dysmorphic disorder. Hubungan yang negatif antara self compassion dengan gejala body dysmorphic disorder yang dimiliki remaja putri, menunjukkan bahwa semakin tinggi self compassion maka semakin rendah gejala body dysmorphic disorder, sebaliknya semakin rendah self compassion yang dimiliki individu maka semakin memungkinkan individu tersebut untuk mengalami gejala body dysmorphic disorder. Sebagai catatan penelitian ini masih menggambarkan gejala body dysmorphic atau bukan diagnosis klinis, dalam menentukan atau menegakkan diagnosis bahwa seorang remaja perempuan menderita body dysmorphic disorder tentu membutuhkan asesmen yang dilakukan oleh ahli, yang bisa di sarankan untuk peneliti selanjutnya.

\section{DAFTAR PUSTAKA}

Albertson, E. R., Neff, K. D., \& Dill-Shackleford, K. E. (2015). Self-Compassion and Body Dissatisfaction in women: A Randomized Controlled Trial of a Brief Meditation Intervention. In Mindfulness. 6.

Allen, Roberts, Gembeck, dan Farrell (2020). Exploring the Relationship between Self Compassion and Body Dysmorphic Symptoms in Adolescents. Journal of Obsessive Compulsive and Related Disorders. 25, 1-8.

Anggraheni, R. D., \& Rahmandani, A. (2019). Hubungan antara Self-Compassion dan Citra Tubuh pada Mahasiswi Program S-1 Manajemen Universitas Katolik Soegijapranata Semarang. Jurnal Empati. 8 (1), 166-172.

American Psychiatric Association. (2013). Diagnostic and statistical manual of mental disorders (5th ed.). Arlington, VA: American Psychiatric Publishing. 
Cash, T. F. (2008). The body image workbook: An eight-step program for learning to like your looks (2nd ed.). New Harbinger Publications.

Cash, T. F., \& Fleming, E. C. (2002). The impact of body image experiences: Development of the Body Image Quality of Life Inventory. International Journal of Eating Disorders, 31(4), 455-460. https://doi.org/10.1002/eat.10033

Braun, T. D., Park, C. L., \& Gorin, A. (2016). Self-Compassion, Body Image, and Disordered Eating: A Review of The Literature. Body Image, 17, 117-131.

Ferreira, C., Pinto-Gouveia, J., \& Duarte, C. (2013). Self-compassion in the face of shame and body image dissatisfaction: Implications for eating disorders. Eating Behaviors, 14(2), 207-210.

Fitri E., Nilma Z., \& Ifdil. (2018). Profil kepercayaan diri remaja serta faktor-faktor yang mempengaruhi. Jurnal Penelitian Pendidikan Indonesia. 4 (1).

Foroughi, A., Khanjani, S., \& Mousavi Asl, E. (2019). Relationship of concern about body dysmorphia with external shame, perfectionism, and negative affect: the mediating role of self-compassion. Iranian Journal of Psychiatry and Behavioral Sciences, 13(2).

Gilbert, P. (2005). Compassion: Conceptualisations, research, and use in psychotherapy. London: Routledge

Gracia, F., \& Akbar, Z. (2019). Pengaruh harga diri terhadap kecenderungan body dysmorphic disorder pada remaja. Jurnal Penelitian dan Pengukuran Psikologi. 8(1), 32-38.

Hurlock E.B. (2003). Psikologi Perkembangan: Suatu Pendekatan Sepanjang Rentang Kehidupan. Alih bahasa: Istiwidayati \& Soedjarwo. Edisi Kelima.Jakarta: Erlangga

Ilma, Khairatul Ulya \& Astuti, Kamsih (2020) Hubungan Antara Self Compassion Dengan Resiliensi Pada Relawan Bencana Alam. Naskah Publikasi Program Studi Psikologi.

Kharina, Kharina, and Juliana I. Saragih. "Meditasi Metta-bhavana (Loving-kindness Meditation) Untuk Mengembangkan Self-compassion." Predicara, vol. 1, no. 1, Sep. 2012.

Moran, B. (2017). Self-Compassion, Body Image Dissatisfaction, and Negative Social Comparisons in Adolescents Utilizing Social Networking Sites. Colleger of Osteopathic Medicine

Neff, K. (2003). The development and validation of a scale to measure self-compassion. Self and Identity, 2(3), 223-250

Papalia, D. E., Olds, S. W., \& Feldman, R. D. (2009). Human development. Jakarta: Salemba Humanika

Phillips, K. (2009). Understanding Body Dysmorphic Disorder. London: Oxford University Press

Raes, F., Pommier, E., Neff, K. D., \& VanGucht, D. (2011). Construction and factorial validation of a short form of the self-compassion scale. Clinical Psychology \& Psychotherapy.18(3), 250-255.

Repi, A. A. (2019). Self Compassion Versus Self Esteem TerhadapPembentukan Self-Concept Remaja: Mana Yang Lebih Baik? Jurnal Psikologi TALENTA, 4(2), 248 - 263. https://doi.org/10.26858/talenta.v4i2.8242 SELF

Rodgers, R. F., Franko, D. L., Donovan, E., Cousineau, T., Yates, K., McGowan, K., Lowy, A. S. (2017). Body image in emerging adults: The protective role of self-compassion. Body Image, 22, 148-155.

Santrock, J. W. (2012). Life span development: Perkembangan masa hidup. Jakarta: Erlangga. Sarwono, S. W. (2006). Psikologi komunikasi remaja. Jakarta: Raja Grafindo Persada.

Sigelman, C.K. \& Rider, E.A. (2017). Life-span Human Development. New York: Wadsworth Publishing. 
Tandy, Elita \& Sukamto, Monique Elizabeth (2013) Asesmen untuk deteksi dini body dysmorphic disorder (BDD) pada remaja perempuan (Assessment to early detect body dysmorphic disorder (BDD) in adolescent girls). Jurnal Psikologi Indonesia, X (2). pp. 78-84. ISSN 0853-3098

Veale, D., \& Gilbert, P. (2014). Body dysmorphic disorder: The functional and evolutionary context in phenomenology and a compassionate mind. Journal of Obsessive Compulsive and Related Disorder, 3(2), 150-160.

Wade, Carol \& Carol, Travis. (2008). Psikologi Jilid 1. Jakarta : Erlangga

Wirasari, I. (2016). Kajian kecantikan kaum perempuan dalam iklan. Jurnal demandia. 1 (2), $146-156$

Wertheim, E.H., \& Paxton, S.J. (2011). Body image development in adolescent girls. In T.F. Cash \& L. Smolak (Eds.2) Body image: A Handbook of science, practice, and prevention. New York: Guilford Press

Yulianto, V. I. (2007). Pesona'barat': analisis kritis-historis tentang kesadaran warna kulit di Indonesia. Bandung: Jalasutra 